\title{
COMORBIDITY OF NON-PSYCHOTIC MENTAL DISORDERS AND NEUROLOGIC SYMPTOMS AMONG YOUNG PEOPLE
}

DOI: 10.36740/WLek202008103

\author{
Valeriy M. Pashkovskyy, Olha S. Yurtsenyuk \\ BUKOVINIAN STATE MEDICAL UNIVERSITY, CHERNIVTSI, UKRAINE
}

\begin{abstract}
The aim: to determine occurrence and structure of non-psychotic mental disorders associated with chronic pain among young people.

Materials and methods: The results of examination of 1235 students were analyzed. The following methods were applied: clinical, clinical-psychopathological, clinicalepidemiological, clinical-anamnestic, experimental-psychological and statistical.

Results: Students with neurotic disorders associated with stress and somatoform disorders were found to prevail in the main group (F40-48.1) 187 (58,99\%), affective mood disorders were on the second position (F30-34.1) - 79 (24,92\%) individuals, followed by disorders of a mature personality and behavior of adults (F60-60.7) diagnosed in 31 (9,78\%) students, and at last, behavioral syndromes associated with physiological disorders and physical factors (F50-51.4) - 20 (6,30\%) respectively. Chronic pain syndrome was diagnosed in $113(35,65 \%)$ students with NMD including $43(38,05 \%)$ men and 70 (61,95\%) women. The majority of young people (86 individuals - 76,11\%) observed severe pain, and 27 (23,89\%) of them - moderate pain. A clear correlation was found between a depressive episode and CPS $(\gamma<0,02)$.

Conclusions: The findings obtained should be considered in development of screening systems concerning diagnostics, prevention of nonpsychotic mental disorders associated with chronic pain syndrome.
\end{abstract}

KEY WORDS: non-psychotic mental disorders, chronic pain syndrome

Wiad Lek. 2020;73(8):1605-1609

\section{INTRODUCTION}

Mental and physical health is inseparably linked. Individuals suffering from mental diseases are under the greatest risk of occurrence of a wide range of neurological symptoms. On the contrary, patients with neurological diseases are depressed and anxious twice as often, than the whole population in general [1]. Coexistence of mental and physical disorders can substantially reduce the quality of life and result in increased duration of disease and deterioration of health. This situation provokes economic loss for the society due to decreased productivity and extended use of medical services. Understanding relations between the mind and body is the first step in development of strategies concerning reduction of comorbid state sickness, an adequate biopsychosocial support of such individuals $[2,3]$.

This pathology is rather topical, since persons with non-psychotic mental diseases often undergo emotional stress and chronic pain, and both these factors are associated with development of neurological symptoms. The experience of getting disability can cause stress as well, and isolate patients from social support. There is a number of evidence that increase of neurological symptoms of disease promote increased probability of problems with mental health $[1,4]$.

Results of numerous researches present convincing arguments that affective disorders of both depressive and anxious ranges are very often associated with chronic pain syndrome (CPS) $[5,6]$. Nevertheless, correlation between the progress of non-psychotic mental disorders and severity of chronic pain and its effect on the quality of life of patients with comorbid pathology has been studied partially and are still being examined.

\section{THE AIM}

To determine occurrence and structure of non-psychotic mental disorders associated with chronic pain among young people.

\section{MATERIALS AND METHODS}

During 2015-2017 we conducted a complete comprehensive examination of the first-fifth-year students of Medical Faculties at Higher State Educational Establishment of Ukraine "Bukovinian State Medical University" (BSMU) and the first-fourth-year students of the Faculty of Pedagogics, Psychology and Social Work, Philological Faculty, the Institute of Physical-Technical and Computer Sciences, Faculty of Mathematics and Informatics, Philosophical-Theological Faculty at Yuriy Fedkovych Chernivtsi National University, keeping to the principles of bioethics and deontology (at the beginning a written consent for participation in the study was obtained from every examined student).

All the students (1235 individuals) were distributed into two groups - the main one (I) and comparison (II). The 
Table 1. Distribution of patients according to diagnoses depending on gender

\begin{tabular}{|c|c|c|c|c|c|}
\hline \multirow{2}{*}{ Diagnosis, rubric according to ICD-10 } & \multirow{2}{*}{ Total number, abs. } & \multicolumn{2}{|c|}{ Males } & \multicolumn{2}{|c|}{ Females } \\
\hline & & abs. & $\%$ & abs. & $\%$ \\
\hline Affective mood disorders (F30-34.1) & 79 & 23 & 23,71 & 56 & 25,45 \\
\hline $\begin{array}{l}\text { Neurotic ones associated with stress and } \\
\text { somatoform disorders (F40-48.1) }\end{array}$ & 187 & 62 & 63,92 & 125 & 56,82 \\
\hline $\begin{array}{l}\text { behavioral syndromes associated with } \\
\text { physiological disorders and physical factors } \\
\text { (F50-51.4) }\end{array}$ & 20 & 3 & 3,09 & 17 & 7,73 \\
\hline $\begin{array}{c}\text { Disorders of a mature personality and } \\
\text { behavior of adults (F60-60.7) }\end{array}$ & 31 & 9 & 9,28 & 22 & 10,0 \\
\hline Total & 317 & 97 & 100,0 & 220 & 100,0 \\
\hline
\end{tabular}

main group included $317(25,67 \%)$ students diagnosed with non-psychotic mental disorders (NMD). To verify clinical signs of NMD 918 (74,33\%) students without NMD, practically healthy, from II comparison group were examined.

852 students (68,99\%) from Higher State Educational Establishment of Ukraine "Bukovinian State Medical University" and 383 students (31,01\%) from Yuriy Fedkovych Chernivtsi National University participated in the study. An average age of the examined students was 20,15 \pm 0,05 years. The gender distribution was the following: 365 men and 870 women, that is $29,55 \%$ and $70,45 \%$ respectively. Sampling did not differ considerably by the sex and age, residence, and form of education. The main criterion to be involved into the study was education at a higher educational establishment. The examinations were conducted in the period between examinations.

The following methods were applied: clinical, clinical-psychopathological, clinical-epidemiological, clinical-anamnestic, experimental-psychological and statistical.

Chronic pain was diagnosed according to the «Unified Clinical Protocol of Palliative Medical Aid in Case of Chronic Pain Syndrome» approved by the Ministry of Health of Ukraine dated 25.04.2012 № 311 [7].

Psychodiagnostic examination was conducted by means of experimental-psychological methods: degree of pronunciation of anxiety symptoms was studied with the help of Spilberger-Khanin test. Degree of depression symptoms was assessed by means of the Zung Self-Rating Depression Scale. The test was adapted at the Department of Narcology, Bekhterev Scientific-Research Institute, by R.I. Balashova. Individual peculiarities were examined by means of the Abbreviated Multiple Factor Questionnaire for Personality Research (Mini-Multi Questionnaire) designed on the basis of MMPI test (Minnesota Multiphasic Personality Inventory). Alexithymia level was determined by means of Toronto Alexithymia Scale (TAS) designed by G. J. Taylor et al. (1985). With the aim to determine neurotism level the technique for the rapid diagnosis of neurosis by K. Heck and H. Hess (BFB complaint scale, 1975) was applied [8].

The main task of clinical-psychopathological method of the study was a comprehensive assessment of a psychic status of an examined person. This method was based on the common approaches to psychiatric examination by means of the interview and observation. The survey was conducted using diagnostic-research criteria of ICD-10.

Semi-structured interview was conducted for all the examined individuals. It considered an individual approach to every student and was directed to find clinical symptoms of NMD according to the diagnostic criteria of Chapter V «Psychic Disorders» of ICD-10. The findings of clinical-psychopathological examination were registered in the supplement to the student's examination chart. The data base of the examined individuals was formed on the basis of both charts (in the format Microsoft Excel XP for Windows) for further statistical processing of the results obtained.

\section{RESULTS}

As a result of the study, non-psychotic mental disorders were diagnosed in $317(25,67 \%)$ students including 97 $(30,60 \%)$ males $(\mathrm{M})$ and $220(69,40 \%)$ females $(\mathrm{F})$.

The Table 1 demonstrates that students with neurotic disorders associated with stress and somatoform disorders prevailed in the main group (F40-48.1) 187 (58,99\%), affective mood disorders were on the second position (F30-34.1) - 79 (24,92\%) individuals, followed by disorders of a mature personality and behavior of adults (F60-60.7) diagnosed in $31(9,78 \%)$ students, and at last, behavioral syndromes associated with physiological disorders and physical factors (F50-51.4) - $20(6,30 \%)$ respectively.

Analyzing NMD comorbidity and chronic skeletal-muscular pain we have tried to determine the degree of NMD effect on pain intensity. Pain is a subjective sensation and experience occurring as a body reaction to the action of harmful, destructive stimuli. From physiological point of view pain is biologically important protective mechanism warning against life threatening danger and promoting maintenance of the whole body. Chronic pain is a danger for the body, causing neurophysiological changes and homeostatic disorders of the entire organism. In case severe pain continues for a long time, chronic pain syndrome develops, which is peculiar for many chronic diseases [7].

Chronic pain syndrome was diagnosed in $113(35,65 \%)$ students with NMD including $43(38,05 \%)$ men and 70 $(61,95 \%)$ women. The majority of young people (86 indi- 
Table 2. Distribution of the stable scales indices of MMPI method according to the categories and united rubrics of ICD-10 considering gender, $M \pm m, T-p o i n t s$

\begin{tabular}{|c|c|c|c|c|c|c|c|c|}
\hline \multirow{2}{*}{$\begin{array}{l}\text { Nonpsychotic mental disorders } \\
\text { (ICD-10 code) }\end{array}$} & \multirow{2}{*}{$\begin{array}{l}\text { Mean } \\
\text { format }\end{array}$} & \multicolumn{7}{|c|}{ Stable scales of MMPI method/№ of scale } \\
\hline & & L/1 & $D / 2$ & $\mathrm{~Pa} / 6$ & $\mathrm{Hs} / \mathbf{1}$ & $\mathrm{Hy} / 3$ & $\mathrm{Sc} / 8$ & $\mathrm{Pt} / 7$ \\
\hline 1 & 2 & 3 & 4 & 5 & 6 & 7 & 8 & 9 \\
\hline \multicolumn{9}{|c|}{ Females } \\
\hline \multirow{2}{*}{ Organic, psychic disorders (F07.2) } & M & 48,03 & 47,82 & & & 48,04 & & \\
\hline & $\pm \mathrm{m}$ & 1,81 & 1,88 & & & 1,89 & & \\
\hline \multirow{2}{*}{ Affective mood disorders (F3) total } & M & 47,57 & 46,22 & 50,57 & 54,10 & 46,88 & 51,41 & 50,40 \\
\hline & $\pm \mathrm{m}$ & 1,44 & 1,27 & 1,94 & 1,03 & 1,31 & 2,03 & 1,77 \\
\hline \multirow{2}{*}{$\begin{array}{l}\text { Disorders associated with impaired mood } \\
\text { F32.0+F34.0+F34.1 }\end{array}$} & M & 46,47 & 48,62 & 51,54 & & 48,18 & 55,32 & 52,13 \\
\hline & $\pm \mathrm{m}$ & 1,62 & 1,74 & 2,48 & & 1,86 & 2,63 & 2,28 \\
\hline \multirow{2}{*}{$\begin{array}{l}\text { Neurotic disorders associated with stress and } \\
\text { somatoform disorders (F4) total }\end{array}$} & M & 46,79 & & 44,64 & 55,03 & & & \\
\hline & $\pm \mathrm{m}$ & 0,77 & & 1,10 & 0,61 & & & \\
\hline \multirow{2}{*}{$\begin{array}{l}\text { Anxiety-phobic and obsessive disorders } \\
\text { F40.0+F40.1+F41.0+F41.2 }\end{array}$} & M & 44,40 & 49,58 & 47,18 & & & & \\
\hline & $\pm \mathrm{m}$ & 2,87 & 3,31 & 3,40 & & & & \\
\hline \multirow{2}{*}{$\begin{array}{l}\text { Response to severe stress and adaptation } \\
\text { disorders F43.20+F43.21+F43.22 }\end{array}$} & M & 47,81 & & & 55,27 & & & \\
\hline & $\pm \mathrm{m}$ & 0,94 & & & 0,68 & & & \\
\hline \multirow{2}{*}{$\begin{array}{l}\text { Somatoform disorders and neurasthenia } \\
\text { F45.0+F45.30+ F45.31+F45.32+ F48.0 }\end{array}$} & $M$ & 43,89 & 51,77 & 53,90 & & 48,82 & & 54,69 \\
\hline & $\pm \mathrm{m}$ & 1,42 & 1,44 & 2,57 & & 1,46 & & 2,87 \\
\hline \multirow{2}{*}{$\begin{array}{l}\text { Behavioral syndromes associated with } \\
\text { physiological disorders and physical factors F50.1 }\end{array}$} & M & 45,31 & & & 51,02 & & 35,76 & \\
\hline & $\pm \mathrm{m}$ & 0,00 & & & 2,49 & & 3,21 & \\
\hline \multirow{2}{*}{ Practically healthy females } & $M$ & 52,29 & 42,90 & 40,08 & 57,00 & 43,71 & 45,99 & 44,48 \\
\hline & $\pm m$ & 0,56 & 0,38 & 0,48 & 0,30 & 0,39 & 0,51 & 0,58 \\
\hline \multicolumn{9}{|c|}{ Males } \\
\hline \multirow{2}{*}{ Organic, psychic disorders(F07.2) } & $M$ & & 52,60 & 54,78 & & 54,91 & 57,27 & \\
\hline & $\pm m$ & & 1,59 & 4,21 & & 2,35 & 3,20 & \\
\hline \multirow{2}{*}{ Affective mood disorders (F3) total } & $M$ & 49,12 & & 57,32 & & & 55,65 & \\
\hline & $\pm m$ & 1,86 & & 3,08 & & & 2,53 & \\
\hline \multirow{2}{*}{$\begin{array}{l}\text { Disorders associated with impaired mood } \\
\text { F32.0+F34.0+F34.1 }\end{array}$} & $M$ & 49,68 & 54,91 & 58,80 & & & 56,79 & \\
\hline & $\pm m$ & 2,27 & 2,61 & 3,56 & & & 2,60 & \\
\hline \multirow{2}{*}{$\begin{array}{l}\text { Neurotic disorders associated with stress and } \\
\text { somatoform disorders (F4) total }\end{array}$} & $M$ & & 52,22 & 51,83 & & & 52,84 & 53,79 \\
\hline & $\pm m$ & & 1,36 & 1,55 & & & 1,66 & 1,54 \\
\hline \multirow{2}{*}{$\begin{array}{l}\text { Anxiety-phobic and obsessive disorders } \\
\text { F40.0+F40.1+F41.0+F41.2 }\end{array}$} & $M$ & 45,10 & 54,29 & 57,10 & & & & 57,74 \\
\hline & $\pm \mathrm{m}$ & 2,93 & 1,88 & 3,93 & & & & 0,82 \\
\hline \multirow{2}{*}{$\begin{array}{l}\text { Response to severe stress and adaptation } \\
\text { disorders F43.20+F43.21+F43.22 }\end{array}$} & $M$ & & & 50,25 & & & & \\
\hline & $\pm \mathrm{m}$ & & & 1,85 & & & & \\
\hline \multirow{2}{*}{$\begin{array}{l}\text { Somatoform disorders and neurasthenia } \\
\text { F45.0+F45.30+F45.31+F45.32+F48.0 }\end{array}$} & $M$ & & 56,43 & 53,73 & & 55,96 & & \\
\hline & $\pm \mathrm{m}$ & & 3,21 & 3,65 & & 3,09 & & \\
\hline \multirow{2}{*}{ Practically healthy males } & $M$ & 54,89 & 48,28 & 44,81 & 62,29 & 48,34 & 48,98 & 49,49 \\
\hline & $\pm m$ & 0,69 & 0,57 & 0,77 & 0,45 & 0,69 & 0,72 & 0,74 \\
\hline
\end{tabular}

viduals - 76,11\%) observed severe pain, and $27(23,89 \%)$ of them - moderate pain. A clear correlation was found between a depressive episode and CPS $(r<0,02)$, enabling to interpret depression as a factor promoting formation of chronic pain syndrome and evidence its psychosomatic etiology.
Specific signs of NMD depressive spectrum availability among the students were: pessimism $(C C=-6,66, \mathrm{~J}=0,64)$, inattention $(\mathrm{CC}=-4,94, \mathrm{~J}=0,51)$, sadness sensation $(\mathrm{CC}=-4,58$, $\mathrm{J}=0,48)$, reduced mental activity $(\mathrm{CC}=-5,54, \mathrm{~J}=0,48)$, impaired mood $(C C=-3,62, J=0,43)$, reserve $(C C=-7,09$, $\mathrm{J}=0,39)$, faintheartedness, tearfulness $(\mathrm{CC}=-6,37, \mathrm{~J}=0,33)$; 
anxiety-phobic spectrum of NMD - anxiety $(C C=-8,80$, $\mathrm{J}=0,67)$; obsession and fear $(\mathrm{CC}=-7,48, \mathrm{~J}=0,58)$, concentration of attention on unpleasant worries $(C C=-5,37$, $\mathrm{J}=0,49$ ), nervousness, sensation of inner tension ( $\mathrm{CC}=$ - 6,57, J=0,45), sensations of heartbeat, «sinking heart», «cardiac arrest», which occur often $(\mathrm{CC}=-4,69, \mathrm{~J}=0,35)$, reduced ability to work (quantitative or qualitative) ( $\mathrm{CC}=$ $-6,39, \mathrm{~J}=0,33$ ), involuntary burst of recollections (figurative, perceptional etc.) $(\mathrm{CC}=-4,77, \mathrm{~J}=0,33)$; asthenic spectrum of NMD - reduced psychic activity $(C C=-5,71$, $\mathrm{J}=0,53)$, headache $(\mathrm{CC}=-4,67, \mathrm{~J}=0,46)$, irritability $(\mathrm{CC}=$ $-5,64, \mathrm{~J}=0,46)$, periods of decreased quick wits $(\mathrm{CC}=$ $-4,75, \mathrm{~J}=0,45)$, reduced ability to work, quick fatigue at the moment $(\mathrm{CC}=-5,32, \mathrm{~J}=0,45)$, sensation of inner tension $(\mathrm{CC}=-4,58, \mathrm{~J}=0,41)$, mental tiredness $(\mathrm{CC}=-4,25, \mathrm{~J}=0,41)$, hypomnesis $(\mathrm{CC}=-2,39, \mathrm{~J}=0,33)$; NMD with prevailing vegetative dysfunction - sensations of heartbeat without excitement or physical exercises $(C C=-4,05, J=0,48)$, reduced ability to work, quick fatigue at the moment $(\mathrm{CC}=$ $-4,58, \mathrm{~J}=0,44)$, periods of headache $(\mathrm{CC}=-4,47, \mathrm{~J}=0,44)$, reduced psychic activity $(\mathrm{CC}=-3,71, \mathrm{~J}=0,39)$, assessment of one's own state of health $(\mathrm{CC}=-3,76, \mathrm{~J}=0,35)$, frequent sensation of difficult breathing: shortness of breath, accelerated respiration $(\mathrm{CC}=-4,27, \mathrm{~J}=0,35)$, sensation of inner tension $(\mathrm{CC}=-4,56 \mathrm{~J}=0,33)$, peristalsis sensations ("butterflies in the stomach") (CC=-4,47, J=0,31).

Specific markers of anti-risk appeared to be of low informative in both groups, and their total values were more important for females only (the lack of $62,5 \%$ of signs according to the rating in our screening enabled to decrease the rate of NMD prognosis and chronic pain syndrome).

\section{DISCUSSION}

We have proved an average degree of accuracy of the following psychodiagnostic scales/indices (rate is according to the values of test-retest correlation): «self-service and independence» (quality of life), $r=0,46$, lie (L) (MMPI), $\mathrm{r}=0,45$, paranoia $(\mathrm{Pa})(\mathrm{MMPI}), \mathrm{r}=0,44$, hypochondriasis (Hs) (MMPI), «physical wellbeing» (quality of life), $r=0,43$, hysteria (Hy) (MMPI), r=0,42, schizophrenia (Sc) (MMPI), $\mathrm{r}=0,41$, psychasthenia (Pt) (MMPI), $r=0,40$. Low reproduction (weak correlation) was registered by the scales and indices of psychopathic deviate (Pd) (MMPI), $r=0,39$, correction (C) (MMPI), $r=0,38$, «general perception of the quality of life» ( «Quality of life» method), $r=0,36$, «intellectual realization» («Quality of life» method), «personality realization» («Quality of life» method), $r=0,33$, relations in the family («Incomplete sentences» method), $r=0,32$, infrequency (F) (MMPI), «integrative index of life quality» («Quality of life» method»), $r=0,31$.

The analysis and interpretation of comparison of the mean values of stable indices are presented below, which reliably $(\mathrm{p}<0,05)$ differed in comparison of the sick and healthy students depending on NMD (according to the gender). They were determined as markers-targets in order to develop psychopreventive and psychocorrection measures.
The distribution of the mean values of the stable indices of D, Pa, Hs, Hy, Sc, Pt scales (MMPI) among the examined individuals by ICD-10 categories and distributed according clinical signs by means of diagnostic rubrics is presented in Table 2 . It should be noted that considering recommendations given by the author of the method we did not analyze the scales within the ranges 46-54 T.

Table 2 presents evidences that both students with NMD and practically healthy ones did not demonstrate perversion of an average personality profile according to L scale. All the values of indices ranged close to mean standard values $(50 \mathrm{~T})$ or were lower, which was indicative of the lack of tendency among the examined individuals to demonstrate themselves in the best advantage (by demonstration of a strict performance of social norms), and a high level of their self-education and culture.

\section{CONCLUSIONS}

Thus, the study conducted has found a direct correlation between depression and chronic pain syndrome among young people. Chronic pain syndrome was diagnosed in $35,65 \%$ students with NMD, and the majority of young people complained of mild pain $(86-76,11 \%)$ and moderate pain - $27(23,89 \%)$. The findings obtained should be considered in development of screening systems concerning diagnostics, prevention of nonpsychotic mental disorders associated with chronic pain syndrome.

\section{REFERENCES}

1. Lahey B.B., Krueger R.F., Rathouz P.J. et al. Validity and utility of the general factor of psychopathology. World Psychiatry 2017;16:142-3.

2. Lee T.Y., Lee J., Kim M. et al. Can we predict psychosis outside the clinical high-risk state? A systematic review of non-psychotic risk syndromes for mental disorders. Schizophr Bull 2018;44:276-85.

3. Rutigliano G., Valmaggia L., Landi P. et al. Persistence or recurrence of nonpsychotic comorbid mental disorders associated with 6-year poor functional outcomes in patients at ultra high risk for psychosis. J Affect Disord 2016;203:101-10.

4. Rydon-Grange M., Coetzer R. What do we know about obsessivecompulsive disorder following traumatic brain injury? CNS Spectr. 2015;20:463-465. doi: 10.1017/S109285291500053X.

5. Avramenko 0.M. Principles of therapy of nonpsychotic mental disorders in patients with chronic pain syndrome: from complex diagnostics to complex supervision. Archive of psychiatry 2016; 22; 1;93-97. (In Ukrainian).

6. Scott E.L. Beneficial Effects of Improvement in Depression, Pain Catastrophizing, and Anxiety on Pain Outcomes: A 12-Month Longitudinal Analysis The Journal of Pain: Official Journal of the American Pain Society. 2016. 17(2). P.215-222.

7. Malkina-Pykh I.G. Psikhosomatika. Moscow: Eksmo; 2008. 1024 p. (In Russian).

8. Unified clinical protocol of palliative care in chronic pain syndrome of the Ministry of Health of Ukraine from April 25, 2012, №. 311. doi:http:// mtd.dec.gov.ua/images/dodatki/311_2012/dod_311_2ykpmd.

\section{ORCID and contributionship:}

Valeriy M. Pashkovskyy: 0000-0001-6066-371X ${ }^{A, B, C, D, E, F}$

Olha S. Yurtsenyuk: 0000-0002-1450-1530 A,B,C,D,E,F 


\section{Conflict of interest:}

The Authors declare no conflict of interest.

\section{CORRESPONDING AUTHOR}

\section{Olha S. Yurtsenyuk}

Bukovinian State Medical University

2 Theater Square, 58000 Chernivtsi, Ukraine

tel: +380501562465

e-mail:yurtsenyuk.olga@bsmu.edu.ua

Received: 02.10.2019

Accepted: 11.06 .2020

\footnotetext{
A - Work concept and design, B - Data collection and analysis, C - Responsibility for statistical analysis,

D-Writing the article, $\mathbf{E}$-Critical review, $\mathbf{F}$ - Final approval of the article
} 